\title{
Jovellanos y la educación
}

\author{
por JoHN H. R. POLT \\ Catedrático de la Universidad de California
}

Las muchísimas obras de don Gaspar Melchor de Jovellanos, a pesar de la inverosímil variedad de los asuntos que tratan, están ligadas por el constante deseo de comprender el pasado y mejorar el presente, preocupación que con frecuencia lleva a su autor a enfrentarse con los problemas de la enseñanza. Y si puede sentarse como regla general que éstos siempre son intrincados y espinosos, los del siglo y de la patria de Feijoo no formaban excepción. No ha de sorprendernos, pues, que les alcanzase esa marea reformadora que fue el reinado de Carlos III.

La enseñanza primaria sufría bajo un sistema de dirección local que permitía disparidades enormes en las condiciones de trabajo, inclusive los salarios, cobrados tarde y mal. Sobre todo después de la expulsión de los jesuitas, dependía económicamente de la caridad de personas particulares, y tendía a concentrarse en las ciudades, dejando sin enseñanza las poblaciones pequeñas. ${ }^{1}$ Se trató de fomentar la instrucción

1. G. Desdevises du Dézert, L'Espagne de l'ancien régime, 3 vols., Parfs, 1897-1904, III (La Richesse et la civilisation), 171; Jean Sarrailh, L'Espagne éclairée de la seconde moitié du XVIIIe siècle, Paris, $1954,43-46,65-68$. 
femenina, muy descuidada antes, con el establecimiento, en Madrid y en 1783, de 32 escuelas gratuitas en las que se enseñaban principios de religión y conducta y algo de costura. Ya que no se pudo extender el dominio gubernamental sobre todo el sistema, se había pensado dar así un ejemplo a otras ciudades; pero la reacción fue más bien escéptica y a veces francamente hostil. La Sociedad Económica Matritense fundó en 1776 las primeras escuelas para niños pobres; en 1788 había ya 64, que enseñaban rudimentos de ciencias y humanidades a los muchachos $\mathrm{y}$ estudios algo más limitados a las muchachas. Para las colonias de Sierra Morena se decretó la enseñanza gratuita y obligatoria, y paso análogo se dio en Navarra en 1795; pero todavía a fines del siglo menos de la cuarta parte de la juventud del país recibía instrucción. ${ }^{2}$

Hasta la mitad del dieciocho no había establecimientos de enseñanza secundaria dirigidos por el Estado; y aun después, la mayoría de ellos seguían en manos de cuerpos independientes y de los municipios. Con el énfasis que venía dándose al trivio de gramática, retórica y lógica, seguía predominando el estudio de la lengua latina, preparación necesaria para la universidad, y se prescindía de la griega y de las modernas, como, por lo común, de la historia, las ciencias naturales y la filosofía no aristotélica. Los colegios de los jesuitas se han considerado los mejores de la época; en ellos aprendía el joven noble algo de historia, economía política, matemáticas, física, navegación y balística, junto con las artes, quizá no menos útiles para él, del baile y de la esgrima. Pero el latín, bien que corrompido a fuerza de ser hablado por los alumnos, seguía formando el núcleo de esta enseñanza, cuyos métodos, a pesar del contenido, en parte bastante moderno, eran en general los de siempre: mucha rutina y mucho aprender de memoria. Al tiempo de su expulsión en 1767 tenían los jesuitas españoles 112 colegios; con su partida descendió necesariamente el nivel educativo del país, bien que sus propiedades confiscadas se aplicaron a la creación de nuevas escuelas. ${ }^{3} \mathrm{El}$ gobierno reformó el Seminario de Nobles de Madrid, antes de la Compañía, y fundó para los plebeyos los Estudios Reales de San Isidro (1770). Ambos establecimientos eran de carácter laico y ofrecían, junto con los estudios tradicionales, cursos de matemáticas y ciencias naturales. Habian de servir de modelos, ya que no existía sistema oficial de

2. Desdevises, III, 170-175; Fernando Díaz-Plaja, La vida española en el siglo XVIII, Barcelona, 1946, 80. Nótese, sin embargo, que John Raymond Perz, Secondary Education in Spain. Washington, 1934, 32, asevera que en los siglos XVI-XVIII "abundaba» la enseñanza para niñat. Este autor da en general más importancia a los establecimientos uindependientes" (en efecto, eclesiásticos) que Desdevises du Dézert, quien se interesa sobre todo por el clesarrollo de la enseñanza oficial.

3. Perz, XI, 20-21, 26-28, 34, 99; Desdevises, III, 176, 178-179; Sarrailh, 186-190. 
enseñanza; pero de hecho tuvieron poco éxito (Desdevises, III, 181-185; Sarrailh, 197).

En las universidades, las violentas controversias filosóficas de la primera mitad del siglo habían desterrado casi del todo el estudio de matemáticas, ciencias naturales y medicina (Perz, 23), hasta tal punto que en 1752 pudo declarar el Marqués de la Ensenada que no existía una sola cátedra de física experimental, de anatomía, ni de botánica; ${ }^{4}$ y por cierto es triste el retraso que de la primera universidad española nos presenta Torres Villarroel en su famosa Vida. Veinte años después habla Cadalso de la "doctísima Universidad [de Salamanca], donde no se enseña matemáticas, física, anatomía, historia natural, derecho de gentes, lenguas orientales ni otras frioleras semejantes», y el mordaz don Tomás de Iriarte escribe: «Se dice que Salamanca es espanto de las ciencias, no porque espanta con ellas, sino porque de tal suerte las ha espantado de sí, que no han vuelto más. $n^{5}$ Algunas universidades, entre ellas la de Alcalá, estaban dispuestas a reformar sus estudios en el sentido que deseaba el gobierno de Carlos III; pero otras, y señaladamente la de Salamanca, seguían oponiéndose tenazmente a todo cambio. En Santiago vacaban 29 de las 33 cátedras; y según un viajero inglés -amigo de España, aunque poco afecto, desde luego, a sus instituciones- algunos estudiantes de Santiago apenas se libraron de la Inquisición por haber procurado instituir conferencia sobre la filosofía experimental al estilo moderno. $3^{6} \mathrm{La}$ resistencia opuesta por los escolásticos a los progresos del racionalismo cartesiano y del empirismo posterior se refleja también en las polémicas surgidas a raíz de la publicación del Teatro crítico universal. Se trataba, en efecto, de una lucha que rebasaba los límites estrictamente filosóficos: los tradicionalistas defendían una educación casi exclusivamente humanística contra la enseñanza científica y utilitaria que iba extendiéndose ya en el extranjero y que propugnaba el gobierno - con poco fruto, a juzgar por la repetición misma de los esfuerzos hasta que en 1807 se llegó a la supresión de once universidades. Este relativo fracaso puede adscribirse a dos factores: la escasez de profesores competentes en las nuevas ciencias que se trataba de fomentar y la adhesión invencible del profesorado existente a los viejos métodos (Desdevises, III, 204-205; Sarrailh, 203).

Parecidos resultados dio la proyectada reforma de los colegios ma-

Thítico universal (Clásicos Canos), 42

. Citados por Emilio Cotarelo y Mori, Iriarte y su época, Madrid, 1897, 127-128, 134 n. 2.

6. Sarrailh, 90-94; [Alexander Jardine], Letters from Barbary, France, Spain, Portugal, \&c. by an English Officer, 2 vols., Londres, 1788, II, 256. 
yores, que de instituciones caritativas se habían convertido en exclusivas de aristócratas. Los colegios se arrogaban funciones de la universidad, ofendiendo así el ideal centralizador de la época, y oprimían a los mantetstas o estudiantes pobres. Los colegiales, en contravención abierta de las leyes universitarias, se vestían con elegancia; se les concedían los grados más fácilmente que a sus compañeros menos afortunados; y ejercían un casi monopolio de los empleos más codiciados del Estado y de la Iglesia, quedándose ilícitamente en los colegios hasta vacar tal empleo. Los esfuerzos gubernamentales no pudieron acabar con estos abusos hasta la supresión de los colegios mayores en 1836 (Díaz-Plaja, 89 y ss.).

El reinado de Carlos III se nos presenta, pues, como período en que estadistas eminentes, entre ellos Aranda, Cabarrús, Campomanes y Olavide, se dedicaban a los problemas educativos.? Sin embargo, es también un período en el cual repetidamente se estrellaron las reformas contra los escollos de la ignorancia, la inercia, la tradición y la suspicacia, y en el cual una censura no muy rigurosa pero sí bastante caprichosa (lo que tal vez sea peor) impedía la importación y la divulgación de las ideas. A la vista está que varias reformas propuestas, aparte de excesivamente ambiciosas, eran francamente anticlericales; pero hay que reconocer al mismo tiempo que a la terca oposición que encontraban en la Iglesia, la Inquisición y las universidades se debe parte de la inquina que llegaron a sentir hacia estas instituciones algunos de los reformadores desilusionados.

Jovellanos había sido favorecido por el Conde de Axanda, a quien debió su nombramiento como alcalde de la cuadra en Sevilla. Su compatriota Campomanes le protegió cuando Ilegó Jovellanos a Madrid en 1778, y estas relaciones amistosas se prolongaron hasta 1790, fecha de la ruptura ocasionada por el proceso de Cabarrús. A este último le conoció Jovellanos en la tertulia de Campomanes; entre los dos nació una amistad mantenida por don Gaspar a costa de grandes sacrificios hasta la adhesión de Cabarrús a la causa bonapartista. Sus relaciones en Sevilla con don Pablo de Olavide, antes del proceso inquisitorial de éste y su subsiguiente huída a Francia, habian sido bastante íntimas. Vemos, pues, que múltiples enlaces personales ligaban a Jovellanos al grupo

7. Véase a este propósito el libro de Sarrailh, Part. II, ch. I, "La Croyance en la culture». 
reformador; pero aun aparte de esto, su ideario político y económico era tal que necesariamente tocaba en los problemas pedagógicos. El llamado despotismo ilustrado presupone la preparación cuidadosa de los dirigentes; una monarquía constitucional, como la que llegó Jovellanos a proyectar para España, requiere la instrucción de unas clases superior y media que den al poder político una base estable e ilustrada. Por esto escribe Jovellanos que

«lo que importa es perfeccionar la educación y mejorar la instrucción pública: con ella no habrá preocupación que no caiga, error que no desaparezca, mejora que no se facilite. En conclusión: una nación nada necesita, sino el derecho de juntarse y hablar. Si es instruida, su libertad puede ganar siempre; perder, nuncas. ${ }^{8}$

Jovellanos creía además que en el mundo moderno el poder político y la fuerza militar estriban en el número y la riqueza de los ciudadanos y que esta riqueza se deriva últimamente de la enseñanza (Oración inaugural, I, 319 b). Para fomentar la agricultura, base de la prosperidad nacional, hay que propagar las ciencias útiles y los procesos agrícolas por medio de institutos especiales y de la instrucción gratuita, pública y universal (LA, II, 123-125). Los adelantos de la industria, necesaria para la elaboración de los productos de la agricultura y para el bienestar económico de las provincias no agrícolas, dependen también de la enseñanza, ya que el progreso tecnológico requerido no puede obtenerse exclusivamente de la ayuda extranjera, escasa además de cara. Repetidas veces clama Jovellanos por «libertad, luces y auxilios» o «buenas leyes, buenas luces y buenos fondos», es decir, "una nación justa, instruida y rica"." Para él como para Adam Smith sólo la instrucción facilita el

8. O, IV, 377 b. Con la abreviaturá O me referiré a la edición B. A. E. de Obras de Jovellanos. Emplear tambien las siguientes abreviaturas: Bases (Bases para la formación de un plan general de instraccion miblica, en O); Calatrava (Gaspar Malchor de Juvellanos, Reglanento para el Colegio de

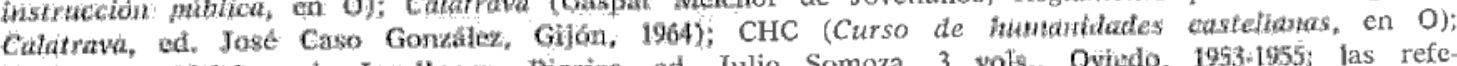
D (Gaspar. Melchor de Jovellanos, Diarios, ed. Julio Somoza, 3 vols.o Ovíto, 1953:1955; las refe-

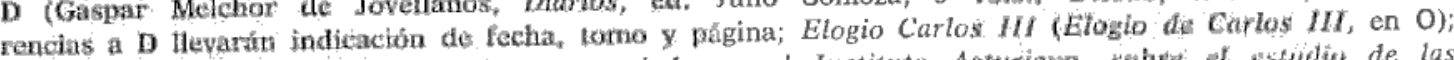
Estudio ciencias naturales (Oración prontinciada en el Instituto Asturiano, sabre el sstudies de las cictoias raturatos, en O): LA (mforme... en al experlieste de ley agraria, en O); Medios (Dikeurso diri

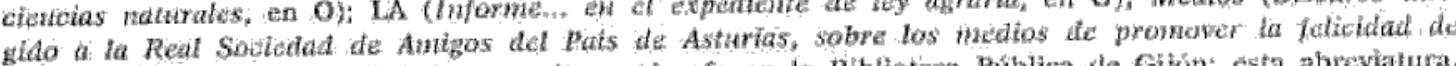
atzel Prikipado, en 0): MSA (manuscrito autógrafo en la Blblioteca Pública de Gijón; esta abreviatura, como la que sigue, va acompañala de un numboro que indica la carpeta en que ste cneverisa el manta crito): MSC (manuscrito, copis - generalmente de Julio Somoza- de la Biblioteca Pública de Gijün):

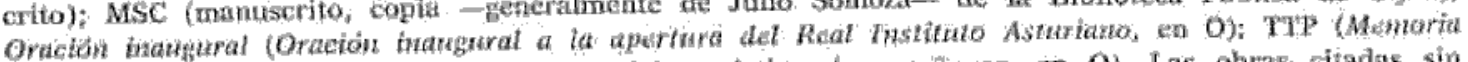
sobre educación publica o sect tratado tedrico-prdetico the enschtana, en 0 ). Las obras citadas sin indicación de atutor son de Jovellanos. Modernizo la ortografín siompré que cito dé edicjones no contemporáneas del autor citado. Se ha discutido la atribuczón a Jovellanos del CHC: sin enjourgo, creo que D, 13.VII.94, I, 454, confirma a don Gaspar como autor por lo menos del "Plan» impreso en $0, \mathrm{I}$, 101-104.

9. Informe sobre sustituir un nuevo método para la hilanza de seda, II, 69 b; Dictamen... sobre embarque de paños extranjeros para nuestras colonias, II, 74 b; Carta a Godoy, IV, 195 b. 
conocimiento del mercado sin el cual no puede funcionar como debiera la perfecta competencia. ${ }^{10} \mathrm{La}$ educación - tanto moral como intelectualreconcilia el interés y la benevolencia, convirtiendo la busca del bien particular en instrumento del bien común.

El comercio interior y exterior, que permitirá el aprovechamiento total de la producción nacional, depende de la mejora de los transportes y de las comunicaciones, y ésta a su vez depende de la educación técnica. Por esto no es casual la preocupación de Jovellanos con el establecimiento del Real Instituto Asturiano de Náutica y Mineralogía, en Gijón, y con la construcción de un camino que enlace a Asturias con Castilla. Para el mismo fin ha de servir la instrucción de los jóvenes en los principios de la economía política y en las prácticas comerciales. La cicncia económica guía la aplicación útil de las descubiertas de las ciencias naturales y es por consiguiente «la verdadera ciencia del Estado, la ciencia del magistrado público». como también "la ciencia del ciudadano y del patriota» (Elogio Carlos III, I, 314 b; Medios, II, 439 b).

Cuando en otro escrito posterior dice Jovellanos que la verdadera fuente del poder político es «el amor público» (TTP, I, 256 b), no cercena la importancia de la educación, puesto que las virtudes cívicas, como luego hemos de ver, son también para él materia de enseñanza. Rechaza, pues, la idea rousseauniana del efecto corruptor de la instrucción y de la civilización. Si bien "una instrucción mala y perversa» puede socavar los cimientos morales del orden público, el remedio se ha de buscar en «la buena y sólida instrucción» (TTP, I, $231 b-232 a, 251 b-252 a$ ). Carlos IV le escribe:

"Cuando yo represento a V. M. la instrucción pública como fuente de tantos bienes, hablo de la instrucción sólida y buena: no de aquella liviana y depravada que es causa de tantos excesos y desórdenes, y que, corrompiendo todos los principios de la moral pública y privada, produce, tarde o temprano, la ruina de los imperios.»11

Además, no se ocupa Jovellanos de la educación sólo por motivos políticos y económicos. Por medio de la política y la economía, la educación ha de contribuir a la felicidad y la perfección de los hombres, cuyo ser, según. Jovellanos, es «el único entre todos dotado de una perfectibilidad indefinida». La educación les permite ejercer sus facultades físicas e intelectuales y perfeccionar su razón por medio del conoci-

10. Jesús Prados Arrarte, "Jovellanos economistan, en Jovellanos: su vida y su obra. Homenaje del Centro Asturiano de Buenos Aires en el bicentenario de su nacimiento, con la adhesión de los Centros Asturianos de La Habana y México, Buenos Aires, 1945, 240.

11. "Discurso al rey sobre un plan de estudios", MSC 3, n.o 37. 
miento. Tal ilustración, en opinión de Jovellanos, hará dichosa a la nación y mejorará la conducta pública y privada, creando por fin una confederación universal y la paz perpetua. ${ }^{12}$ ¿Podría hallarse mejor ejemplo del optimismo tal vez ingenuamente entusiasta de aquella edad?

Todos estos ideales — políticos, económicos, filantrópicos- se relacionan en la mente de Jovellanos con la educación, y por esto cree que «el bien público exige que la buena y liberal instrucción se comunique a la mayor porción posible de ciudadanos» (TTP, I, $234 a$ ).

«Obsérvese - escribe- que la utilidad de la instrucción considerada políticamente no tanto proviene de la suma de conocimientos que un pueblo posee, ni tampoco de la calidad de estos conocimientos, cuanto de su buena distribución" (TTP, I, $241 b$ ),

Esto quiere decir específicamente que no debe limitarse la instrucción a los pocos sino hacerse asequible a ambos sexos y a todas las clases, especialmente a las inferiores, que no tienen más medios de mejorarse que cuantos les proporcione el gobierno (TTP, I, $234 b, 241 b-242 a$ ). Para facilitar la enseñanza primaria, que requiere en los maestros calidades morales más bien que intelectuales (TTP, I, $242 b-243 a$ ), Jovellanos sugiere que la puede dar el clero (LA, II, 125 b). En general, favorece un sistema de enseñanza laica bajo la dirección del Estado; pero aquí, como en otras ocasiones, se niega a ser doctrinario y adapta la teoría a las exigencias de la práctica.

Pero la educación no es sólo un derecho. Cada hombre está obligado a instruirse respecto a sus deberes cívicos y los de su puesto particular en la sociedad. Los padres tienen además la obligación de desarrollar las facultades físicas e intelectuales de sus hijos, enseñándoles también sus deberes y preparándolos para ejercer su profesión. ${ }^{13}$ Esta obligación paterna la concibe Jovellanos no tanto para con el niño como para con el Estado o la sociedad, porque si el bienestar público consiste en la suma de bienestares particulares, "the pursuit of happiness» no es sólo un derecho sino un deber. Estos mismos fines de la educación los propone Rousseau, el cual, habiendo declarado que hacer un hombre es incompatible con hacer un ciudadano, concluye sin embargo que

«un père, quand il engendre et nourrit des enfants, ne fait en cela que la tiers de sa tâche. Il doit des hommes à son espèce, il doit à la société des hommes sociables; il doit des citoyens à l'état».14

12. Estudio ciencias naturales, I, 340-341; TTP, I, 231 a, 232 b, 255 a; Elogio Carlos III, I, 314 b, 317 a; Carta a Vargas Ponce, II, 268 b; MSC 3, núm. 58, carta 3.

13. TTP, I, 257; MSC 3, n.0 14; MSC 3, n.o 58, carta 7.

14. Jean-Jacques Rousseau, Emile (en CEuvres completes de J. J. Rousseau, ed. P. R. Auguis), 3 vols., Paris, 1824, I, 15-16, 39. 
Para Jovellanos el deber de instruirse es tan importante que propone, como antes lo había hecho Adam Smith, cercenar los derechos y los privilegios de quienes no hayan recibido por lo menos la instrucción primaria. ${ }^{15}$ A los nobles los exhorta repetidamente a hacerse dignos de su posición social, a sobresalir intelectual y moralmente a la vez que sobresalen por sus "pergaminos» (Oración inaugural, I, $323 a$; TTP, I, 234 a); y dirigiéndose a Carlos IV escribe que

"no hay bien que no pueda alcanzarse; no hay mal que no se pueda evitar y destruir por medio de la instrucción que es el efecto y el fin de la educación; ella es por quien las Naciones prosperan; y sólo por su falta decaen y se arruinan» (MSC, $3, n^{\circ}{ }^{\circ} 37$ ).

La educación española de su tiempo cuadraba mal con los ideales de Jovellanos.

Como ya medio siglo antes lo había hecho el P. Feijoo, ese gran iniciador de todo lo mejor que daría de sí la Ilustración española, Jovellanos condena la filosofía aristotélica por haber ensalzado la especulación a expensas de los conocimientos empíricos. El equivocado método del Peripato había cerrado las puertas de la sabiduría; «la gloria de abrirlas de par en par estaba reservada al sublime genio de Bacon". Si bien el tono es más duro que en el Teatro crítico, recordemos la admiración del benedictino de San Vicente por el mismo Bacon y su empirismo. Pero Jovellanos va más allá en sus ataques. Según él, la filosofía aristotélica, deformada por los árabes y por los comentaristas ignorantes, ha llegado a ser «el mejor escudo de las preocupaciones generales." Sus sofisterías han corrompido los estudios teológicos distrayendo la atención del análisis directo de las fuentes. ${ }^{16} \mathrm{~A}$ los alumnos del Real Instituto Asturiano les promete Jovellanos que

«no se tratará en él de ofuscar vuestro espíritu con vanas opiniones ni de cebarle con verdades estériles; no se tratará de empeñarle en indagaciones metafísicas, ni de hacerle vagar por aquellas regiones incógnitas donde anduvo perdido tan largo tiempo. ¿Qué es lo que puede encontrar en ellas la temeraria presunción del hombre? Desde Zenón a Espinosa y desde Thales a Malebranche, ¿qué pudo descubrir la ontología, sino monstruos o quimeras o dudas o ilusiones? ¡Ah! sin la revelación, sin esta luz divina, que descendió del cielo para alumbrar y fortalecer nuestra oscura, nuestra flaca razón, ¿qué hubiera

15. Bases, I, 270 a; Adam Smith, An Inquiry into the Nature and Causes of the Wealth of Nations, ed. Edwin Cannan, Nueva York, 1937, bk. V, ch. I, part III, article II. Smith, sin embargo, se opone generalmente a la educación pública costeada por el Estado.

16. Elogio Carlos III, I, 313 a, 314 a; Calatrava, 152-153, 171; Estudio ciencias naturales, I, 336. Cf. Feijoo, Teatro critico universal, especialmente VII, disc. 011, y VIII, disc.0 1 a 3. 
alcanzado el hombre de lo que existe fuera de la naturaleza? ¿Qué hubiera alcanzado aun de aquellas santas verdades que tanto ennoblecen su ser y hacen su más dulce consolación?" (Oración inaugural, I, $320 a$; cf. Elogio Carlos III, I, 314 b).

Lo mismo que Locke, y dejando a salvo la importancia de la revelación, Jovellanos insiste aquí en los límites del «entendimiento humano" que hacen inútil y aun perniciosa la especulación metafísica. Se trata, por supuesto, de un lugar común de la crítica «ilustrada» que encontramos, igual que en Locke, en Adam Smith:

«But if subtleties and sophisms composed the greater part of the Metaphysics or Pneumatics of the schools, they composed the whole of this cobweb science of Ontology, which was likewise sometimes called Metaphysics" (726);

en la "Confession de foi du vicaire savoyard":

«Les idées générales et abstraites sont la source des plus grandes erreurs des hommes; jamais le jargon de la métaphysique n'a fait découvrir une seule vérité, et il a rempli la philosophie d'absurdités dont on a honte, sitôt qu'on les dépouille de leurs grands mots» (Rousseau, Emile, II, 156);

y en Voltaire, por no citar a otros :

«Toute la métaphysique contient deux choses: la première, ce que tous les hommes de bon sens savent, la seconde, ce qu'ils ne sauront jamais.. ${ }^{17}$

Esto no obsta a que el mismo Jovellanos, al trazar sus propios planes de estudios, incluya en ellos elementos de ontología, los cuales, sin embargo, parecen consistir en nociones de epistemología sensualista $(\mathrm{CHC}, \mathrm{I}$, $101 b$; TTP, I, $249 b$ ).

También condena Jovellanos la teología tomística, aunque con reservas. La Suma teológica, por grande que sea, le parece de poco provecho para los estudios elementales y para la defensa de la Iglesia contra sus enemigos modernos. Está mermada su coherencia por la supresión, de orden real, de ciertos artículos; y adolece de su conexión con la escolástica y de la "falta de crítica» reinante en los tiempos de su autor. Por esto prescribe Jovellanos como lectura suplementaria de los colegiales de Calatrava el Curso teológico lugdunense. ${ }^{18}$ Casi veinte años después de comenzada la reforma universitaria, los cursos teológicos

17. CEuvres complètes, ed. Moland, París, 1879, XXXIV, 249

18. Calatrava, ECL. Sobre las Instituciones theologicale o Curso teológico lugdunense, véase José Caso González, «Escolásticos e innovadores a finales del siglo xviri (Sobre el catolicismo de Jovellanos)" Papeles de Son Armadans, n.o CIX (1965), 25 y ss. 
de Salamanca le parecen tan "defectuosos y prepósteros» que el tiempo pasado en ellos es tiempo perdido para la «ilustrada y metódica enseñanza» (Calatrava, 155). Esta ha de evitar todo contacto con las sectas escolásticas, de las que sólo sabrán los colegiales lo necesario para condenarlas. En las polémicas se han de evitar la sofistería y los argumentos frívolos, como también los abusos del método silogístico conducentes a aquellos males. En esta condenación volvemos a ver reflejos del pensamiento "ilustrado" y especialmente de Locke y de Condillac..$^{19}$

Los resultados de la tradición en su propia formación intelectual los describe Jovellanos de esta manera:

«En mis primeros estudios segui sin elección el método regular de nuestros preceptores. Me dediqué después a la filosofía, siguiendo siempre el método común y las antiguas asignaciones de nuestras escuelas. Entré a la jurisprudencia sin más preparación que una lógica bárbara y una metafísica estéril y confusa, en las cuales creía entonces tener una llave maestra para penetrar al santuario de las ciencias. Mis propios directores miraban como inútiles los demás estudios, incluso el de la historia. $\$^{20}$

A pesar de esta crítica y de otras parecidas se ha dicho que Jovellanos fue en el fondo escolástico. ${ }^{21}$ Conviene tal vez precisar. Por cierto no rechaza cuanto enseñaran los escolásticos, gran parte de lo cual, perteneciente al fondo común de cualquier filosofía, es aceptado por los pensadores del siglo xvir. En cambio, el método deductivo le parece poco útil en la enseñanza, como en general mucho de la escolástica le parece inútil para la juventud lega de un país que necesita mejoras materiales y económicas. La metafísica y ontología que incluye en sus planes de estudios no creo que pasen de ser una introducción muy elemental para niños, al mismo tiempo que es innegable que su ideología se deriva en gran parte de Locke y, tal vez más, de Condillac. Supongo que así comprendiera a Jovellanos la misma Universidad de Oviedo, cuando en 1811 expresó la esperanza de que la ayudara a liberarse de las «tinieblas del escolasticismo» $\mathrm{y}$ "las cadenas de la preocupación» (O, IV, $499 a)$.

19. Calatrava, 153, 169-170, 208. Cf. John Locke, Of the Conduct of the Understanding (en The Educational Writtings of John Locke, ed. John William Adamson), Cambridge (Inglaterra), 1922, n.0 33; I ocke, An Essay Concerning Human Understanding, ed. Alexander Campbell Fraser, 2 vols., Nueva York, 1959, bk. III, ch. X, y bk. IV, ch. XVII; Louis Robert, Les Théories logiques de Condillac, París, $1869,79$.

20. Discurso... sobre la necesidad de unir al estudio de la legislación el de nuestra historia y antigiedades, I, $288 \mathrm{~b}$.

21. Juan Luis Villota Elejalde, Doctrinas filosófico-jurílicas y morales de Jovellanos, Oviedo, 1958, 20, 23-28. 
El hecho de que en la mayoría de las universidades, semieclesiásticas y relativamente libres del control gubernamental, dominaran aún los métodos escolásticos, mientras se excluían los estudios prácticos y los experimentales, explicará la actitud de Jovellanos frente a estas instituciones. No siempre es hostil a ellas, pero busca la mejora educativa fuera de sus aulas, ${ }^{22}$ sobre todo en la enseñanza secundaria, desorganizada por la expulsión de los jesuitas y menos dominada por la tradición reacia. Desde luego es ésta una actitud corriente en la Europa del siglo xviII. Condorcet creía que todo cuerpo perpetuo mantiene ideas "hereditarias» en perjuicio de la educación; el amigo de Jovellanos, Alexander Jardine, propuso que se abandonasen "those monkish institutions called universities"; y Adam Smith, para quien las universidades eran los últimos refugios de "sistemas desautorizados y prejuicios anticuados", declaró también que «in the university of Oxford, the greater part of the public professors have, for these many years, given up altogether even the pretence of teaching. ${ }^{23}$ Los estadistas españoles

«n'attendaient rien de bon des Universités et ne tentèrent de les réformer que par acquit de conscience. Désespérant de s'emparer jamais de ces vieilles bastilles, ils imaginèrent d'organiser à côté d'elles des instituts d'une structure plus moderne, qui devaient peu à peu attirer à eux toute la vie scientifique du pays» (Desdevises, III, 205).

Como tantos contemporáneos suyos, Jovellanos creía que la educación liberal y científica no correspondía a las universidades; abandonada toda esperanza de implantarla allí, vuelve a recomendar que estos establecimientos enseñen las ciencias «intelectuales» o «especulativas», mientras se cultivan las prácticas en institutos públicos especiales, de los que él mismo había creado uno (Noticia del $R$. Instituto Asturiano, II, 392; TTP, I, $236 b$; Bases, I, $271 b$ ).

Al tratar del control de la educación refleja Jovellanos la tendencia centralizadora de la Ilustración española. Después de criticar duramente los conatos de autonomía educativa que ha observado en el Colegio de Calatrava, declara que en adelante cualquier cambio del reglamento necesitará la aprobación del Real Consejo de Ordenes (Calatrava, 38-39). En 1809 propone que se estudie la conveniencia de uniformar los mé-

22. LA, II, 124 b. Véase Felipe Bareño, Ideas pedagógicas de Jovellanos, Gijón, 1910, 17; María Angeles Galino Carrillo, Tres hombres y un problema: Feijoo, Sarmiento y Jovellanos ante la educación moderna Madrid, 1953, 199; Hilario Yaben Yaben, Juicio crítico de las doctrinas de Jovellanos en lo referente a las ciencias morales y polfticas, Madrid, 1913, 127-128.

23. Condorcet, Sur l'instruction publique (en Euvres completes, 21 vols., Brunswick y París, IX), 1804, 53; Jardine, II, 146-147; Smith, 718, 726-727. 'V. Edith F. Helman, reseña de Sarrailh, Hispanic Review, XXIII (1955), 318. 
JOHN H. R. POLT

todos y libros de texto de todas las instituciones sin que se imponga empero "una estabilidad dañosa a los progresos de las ciencias» (Bases, I, $274 b$ ); y esta regulación gubernamental se ha de extender incluso a las escuelas privadas (Bases, I, 273 b). Se deja sentir aquí la oposición al predominio eclesiástico, oposición explícita en el informe que Jovellanos, ministro de Gracia y Justicia, somete a Carlos IV en 1798. Describiendo el estado de la Universidad de Salamanca, se lamenta el ministro de la división entre aristotélicos y modernos; aquéllos acusan a sus enemigos de impíos, mientras que éstos

«se vengan imputándoles el empeño de resistir toda reforma de los estudios y hacer la guerra a toda ilustración para conservar sus añejas opiniones: su adhesión a las usurpaciones de la curia romana, su aversión a la autoridad soberana y sus regalías, su ambición de dominar las escuelas, de conservar la influencia de los regulares en ellas $y$, en una palabra, de perpetuar la ignorancia.

„iQué sabiduría, qué prudencia, qué virtud no necesita un prelado puesto a la vista de esta escuela general, que por desgracia parece todavía un establecimiento esclesiástico!» (O, V, 293, $b-294 a)$.

Ya antes ha propuesto que los canonistas estudien las relaciones entre Iglesia y Estado y la historia de la intervención de éste en la disciplina exterior eclesiástica (Calatrava, 180-181, 188). La tendencia de estos comentarios y recomendaciones está clara: se trata de reemplazar la dominación eclesiástica en la educación por la dirección laica del gobierno central - paso que en efecto no se dio en España hasta el siglo XIX.

El epítome de los fines pedagógicos que se proponía Jovellanos es el lema del Instituto Asturiano: Quid verum, quid utile, palabras que también servirían de lema a Locke, a Rousseau y a Feijoo, quien había escrito: "No hay verdad alguna, cuya percepción no sea útil al entendimiento, porque todas concurren a saciar su natural apetito de saber. $\rangle^{24}$ Los estudios que servían este doble fin eran precisamente los más descuidados en la España del siglo xviıI. Fundamentales para ellos son las matemáticas, que son para Jovellanos entrenamiento intelectual, instrumento de las ciencias físicas y modelo del conocimiento. Las ciencias intelectuales sólo se pueden "elevar» a la exactitud de las «demostrativas»

24. Locke, Conduct, n.o 25; Rousseau, Emile, I, 322; Feijou, Cartas eruditas y curiosas, II, carta 16, n.0 11 . 
dando a la terminología filosófica la misma correspondencia exacta entre conceptos y palabras que rige en las matemáticas (TTP, I, 250 b). A Jovellanos, como antes a Descartes y a Locke, le impresiona el «método geométrico»; la epistemología de la Ilustración aparece en el aserto de que la geometría

«es la verdadera lógica del hombre, pues ocupándole en la demostración de verdades ciertas e indubitadas, y acostumbrándole a desechar toda idea que no sea exacta, clara y distinta, es la que verdaderamente le enseña a discurrir con orden y precisión y a discernir y desechar los errores que encuentra en el caminos. ${ }^{25}$

Ya Feijoo había recalcado lo inútil de toda física que no fuera experimental, llegando a declarar que "los experimentales... en la realidad son los únicos Filósofos» (Teatro crítico universal, VII, disc. ${ }^{\circ} 13$, n. $^{0} 19$ ); y para Jovellanos también "la física puramente especulativa será siempre más dañosa que útil. La física que yo desearía debe ser experimental» (Carta a Prado, II, 146 a). El método empírico de esta ciencia contrarrestará la especulación metafísica, ${ }^{26}$ además de ser la ciencia misma la base técnica del progreso económico. Pero su fin, el de aplicar útilmente el conocimiento de la naturaleza, marca también los límites de la investigación científica, que cuando rebasa lo útil es vana y presuntuosa (Ordenanza para el R. Inst. Ast., II, 413 a, 415 a; Oración inaugural, I, 322 b). Como Locke, Jovellanos distingue entre la hipótesis científica y el verdadero conocimiento; condenando la ignorancia supersticiosa que se opone al estudio de la obra divina en la naturaleza, también previene contra el orgullo impío de los que quieren escudriñar la naturaleza sólo para atribuirla al azar o a una necesidad impersonal. ${ }^{27}$ Jovellanos, utilitario cuando exige los estudios científicos, lo es también cuando señala sus límites.

La aplicación de estas ciencias y el fomento del comercio requieren, según vimos antes, el estudio de los principios económicos y comerciales, enseñanza que aconseja Jovellanos a las instituciones dedicadas a Ia «filosofía práctica» (Bases, I, 272 a-273 a). También es imprescindible el estudio de la historia; pero ésta es para Jovellanos, como para Rousseau, inútil y dañosa si se ciñe a enumerar guerras y batallas. Para explicar

25. Carta al Doctor Prado... sobre el método de estudiar el derecho, II, 146 a. Cf. Locke, Conduct, núm. 6, Essay, bk. III, ch. X, núm. 5, y bk. IV, ch. XII, núm. 7; Condillac, Essai sur l'origine des conoissances humaines, París, 1798, 458 y ss.

26. Oración... sobre la necesidad de unir el estudio de la literatura al de las ciencias, I, 330 b.

27. Estudio ciencias naturates, I, $340 \mathrm{~b}, 342 \mathrm{~b}$; John Locke, Some Thoughts Concerning Education, ed. R. H. Quick, Cambridge (Inglaterra), 1913, n. 190. 
los orígenes de las instituciones políticas y sociales, junto con sus cambios -el «espíritu de las leyes»- debe ser "una historia civil.» ${ }^{28}$

En la educación que propone Jovellanos las humanidades, o sea el "arte de pensar, de hablar y escribir bien», se justifican como fuente del "buen gusto", "el talento más necesario en el uso de la vida». ${ }^{29} \mathrm{Ya}$ que el latín se requiere para ciertos estudios universitarios, Jovellanos pide que sea obligatorio para cuantos lo necesiten, pero electivo para los demás. Así se evitarán dos males: la pérdida de tiempo para otros estudios, y la tentación en que se ven muchos jóvenes de las «clases industriosas" a "salir de ellas con tan poco provecho suyo como con gran daño del Estado» (TTP, I, 243 b-245 a; Bases, I, 271 a). Además, por importante que sea el latín, no lo es el hablarlo, práctica que entre escolares sólo corrompe la pureza gramatical (Calatrava, 130, 206-207). Y menos aún justifica esa importancia la enseñanza en latín, que da lugar a este sarcasmo:

«...La lengua latina, por razones que se esconden a mi pobre razón, se ha levantado a la dignidad de único y legal idioma de nuestras escuelas [i. e., universidades], y lo que es más, se conserva en ellas a despecho de la experiencia y el desengaño» (T'TP, I, 237 a. Cf. Bases, I, 270 b; Carta a Prado, II, 145 a).

La lengua castellana debería adoptarse como la de toda enseñanza, incluso la universitaria. ${ }^{30}$

Jovellanos pide el estudio sistemático y mejoramiento de la lengua vulgar, extendiendo este interés a las lenguas y dialectos regionales, como el mallorquín, el vascuence y por supuesto el bable. ${ }^{31}$ Tanto más importante es este estudio para él cuanto cree que la lengua es el instrumento necesario del análisis, o sea, del pensamiento en general, puesto que "pensar es hablar consigo mismo»(TTP, I, 240; Carta a Prado, II, $145 \mathrm{~b}$ ). Es ésta una posición que se acerca a la de Locke y que es prácticamente idéntica a la de varias obras de Condillac, señaladamente su

28. Discurso... sobre la necesidal de... estudio... de nuestra historia y antigiledades, I, 298; Rousseau, Emile, I, 191, II, 68-69, 73. Cf. Locke, Thoughts, n.o 182.

29. Calatraya, 129; Oración... sobre la necesidad de tunir el estudio de la literatura al de las ciencias, I, $332 \mathrm{~b}$. V. también José Caso González, "Las humanidades en el pensamiento pedagógico de Jovellanos», conferencia editada en Real Instituto de Jovellanos, Memoria del curso 1961-1962, Gijón, 1963. No comparto la opinión de Galino, 248, quien ve aquí la rectificación de una oriestación exclusivamente utilitaria. Ni el utilitarismo de Jovellanos es exclusivo, ni dejan de ser útiles, para él, las humanidades.

30. Bases I, 270 b. Semejante propuesta la había hecho Llull en su Ars puerilis (Perz, 13), obra que conoció Jovellanos en Mallorca (O, V, 99).

31. Carta a Prado, II, 145 b-146 a; TTP, I, 245 b; D, 14.IX.97, II, 411. Cf. Locke, Thoughts, núms. 168, 171-173, 189. 
Lógica. Al estudio de la gramática castellana ha de preceder el de la general, es decir, de unos elementos de linguística divorciados de cualquier lengua específica (TTP, I, 245 b; CHC, I, $101 a$ ).

El sistema corriente de enseñar las humanidades por medio de reglas y preceptos le parece a Jovellanos lento e inadecuado a la edad de los alumnos; por esto pide mayor empleo de ejemplos y modelos (Calatrava, 129; Bases, I, 270 a). El mismo método se ha de seguir con las lenguas extranjeras; pero a diferencia de Locke, quien supone que el alumno perfeccionará su conocimiento hablando con su ayo, Jovellanos se contenta con que los estudiantes aprendan a traducir. ${ }^{32}$

Las lenguas modernas, y sobre todo el inglés y el francés, son las más importantes para cualquier carrera práctica. ${ }^{33}$ Por cierto es venerable el mito del "afrancesamiento" de la vida intelectual española en el siglo XvIrr; pero miremos el juicio de Jovellanos sobre los méritos de las lenguas francesa e inglesa:

"Y ahora, si alguno que sólo quiera estudiar una de estas lenguas preguntare cuál debe preferir, le diré que la francesa ofrece una doctrina más universal, más variada, más metódica, más agradablemente expuesta, y sobre todo, más enlazada con nuestros actuales [1802] intereses y relaciones políticas; que la inglesa contiene una doctrina más original, más profunda, más sólida, más uniforme y, generalmente hablando, más pura también, y más adecuada a la índole del genio y carácter español; y que, por tanto, pesando y comparando estas ventajas, podrá preferir la que más acomodase a su gusto y sus miras.»

Lo mejor, por supuesto, sería estudiar las dos (TTP, I, $248 a$ ).

Se ve que Jovellanos no se opone a una «tête bien pleine», ni tiene esa desconfianza en el intelecto del niño por la que Rousseau quiere dejar casi toda instrucción formal hasta los últimos años de la adolescencia. Pero no sólo en los estudios nuevos - economía política, lenguas modernas, humanidades castellanas, ciencias naturales- se diferencia el programa de Jovellanos del de la escuela tradicional, casi exclusivamente humanístico y orientado hacia el latín. También se destaca don Gaspar por el interés que le inspira el estudiante como hombre, y de ahí su preocupación por ciertas materias y por los métodos pedagógicos y la disciplina.

32. CHC, I, 106 a, 114 b; TTP I, 248 b; Ordenanza para el R. I. A., II, 412 a; Locke, Thoughts, nos. 163167. Locke cree que el estudio de lenguas extranjeras debe empezar en cuanto el niño sepa la materna; Jovelianos, que a los 11 ó 12 años; Rousseau, Emile, I, 182, que es inútil $y$ generalmente imposible antes de los 12 o 15 .

33. TTP, I, 243 b, 248 a. Cf. Bases, I, 271 b; Carta a Prado, II, 145 b; D, 20.VII.94, I, 463; y Feijoo, Cartas eruditas y curiosas, V, carta 23. 
Los grandes objetos del saber son para él la naturaleza, el hombre y Dios (TTP, I, 239). El conocimiento de Dios se ha de impartir por el estudio de la religión, del catecismo. La lógica, que Jovellanos también llama ideología, ha de iluminar la naturaleza del hombre y explicar sus relaciones con sus semejantes y su Criador. Estudiará el alma, sus facultades, las impresiones que le llegan por los sentidos, las ideas de causalidad y de una primera causa, y los principios de la ética.

«En suma, nuestra ideología deberá reunir y enlazar en el orden indicado por su misma naturaleza las ideas principales de la dialéctica, psicología, cosmología, ontología, teología natural y ética; en una pálabra, todos los principios de la filosofía racional [i. e., la no "natural" o "práctica»]» (TTP, I, 249).

El estudio experimental de las operaciones del alma, o sea el análisis introspectivo, se ha de fomentar en los alumnos bajo la dirección de sus maestros y de la "muy perspicua y sólida doctrina» de Locke y Condillac (TTP, I, 250 b). La ética, incumbencia primaria de los padres, deberá también enseñarse en las escuelas como disciplina no meramente teórica, sino práctica (TTP, I, $235 a, 251,260$ b). La creencia en «una moral de sentimiento", que, sin embargo, debe cultivarse y perfeccionarse por medio de la educación, recuerda a Godwin y más directamente a Hutcheson, mientras que el énfasis en el aspecto práctico de tales estudios refleja a Locke. ${ }^{34}$ Este aspecto lo explica Jovellanos en carta a Godoy (O, IV, 199 b-200 b) y más tarde en las Bases para la formación de un plan general de instrucción pública, donde se enumeran las virtudes sociales que ha de inculcar la enseñanza:

«El amor a la patria, el odio a la tiranía, la subordinación a la autoridad legítima, la beneficencia, el deseo de la paz y orden público, $\mathrm{y}$ todas las virtudes sociales que forman buenos y generosos ciudadanos, y conducen para la mejora de las costumbres, sin las cuales ningún estado podrá tener seguridad ni ser independiente y feliz» (I, 272).

34. Introducción a un discurso sobre el estudio de la economía civil, V, 12; William Godwin, Enquiry Concerning Political Justice and its Inftuence on Morats and Happiness, ed. F. E. L. Priestley, 3 vols., Toronto, 1946, I, 309-311; Francis Hutcheson, A System of Moral Philosophy, 2 vols., Glasgow, 1755, I, 53-79; Locke, Thonghts, n. 185. Sobre si fuc Jovcllanos el autor de la citada Introđucción puede verse Juan Agustín Ceán Bermúdez, Memorias para la vida del Excno. Señor D. Gaspar Metchor de Iove Llanos, y noticias analiticas de sus obras, Madrid, 1814 [1820], 17; Julio Somoza, Inventario de tur jovellanista. Madrid, 1901, 85-86; Somoza, Jovellanos: manuscritos inéditos, raros, o dispersos, Madrid, 1913, 11-14; Harold Lowe Dowdle, "The Humanitarianism of Gaspar Melchor de Jovellanos", tesis doctoral inédita de la Universidad de Stanford, 1954, 238 y ss. Dowdle, chyos argumentos no me es dable reproducir aquí, hace una defensa a mi ver convincente de la autenticidad del escrito y de la atribuciún que hace Ceán contra las objeciones puestas por Somoza. Villota, 163, se sorprende al ver que Jovellanos proclama la necesidad de estudiar las ciencias morales wen pleno apogeo de las ciencias útiles». Pero no es inútil la ética para Jovellanos, ni es tan exclusiva "la obsesión de los dieciochescos" con la utilidad, 
Uno de los principales fines de esta enseñanza es el de contrarrestar las ideas revolucionarias y subversivas (TTP, I, $251 b-252 a$ ).

Las reglas que da Locke para la salud y el desarrollo físico se reflejan en algunos escritos de Jovellanos, que fue uno de los primeros españoles en ocuparse de estas cuestiones (Galino, 222; Bareño, 38). Aunque había declarado que la educación física incumbe a los padres, durante la Guerra de la Independencia propone que se haga obligatoria para todos los ciudadanos y que se le añada la instrucción militar. En ésta ha de figurar la perfección de los sentidos, recuerdo de Pestalozzi y de Rousseau. ${ }^{35}$

Las ideas de Jovellanos sobre los métodos pedagógicos también reflejan las de Locke. Aborrece al pedante y quiere que se cultive en los alumnos el deseo de instruirse. ${ }^{36}$ Los jóvenes deben aprender "el arte de resumir y extractar», del que fue maestro el mismo Jovellanos; así se perfeccionarán también en el análisis (TTP, I, 246 b), por el cual y por la inducción (en vez de la deducción silogística) se adquieren los conocimientos (TTP, I, 250; Calatrava, 130. Cf. Locke, Conduct, n. 0 39). La lectura meditada de los textos ha de reemplazar el aprenderlos de memoria (Calatrava, 131-132, 170. Cf. Rousseau, Emile, I, 192).

Algunas de las teorías pedagógicas de Jovellanos nos parecerán discutibles. Creyendo que el estudio de la cognición facilita el de las demás ciencias, quiere que las preceda. ${ }^{37}$ Una mala lectura de Bacon lleva al aserto de que el estudio de toda ciencia debe empezar con su historia (Calatrava, 154; Ordenanza para el $R$. I. A., II, 412 b). También podría dudarse que para el adolescente el estudio de las lenguas extranjeras resulte más fácil después de aprendida «la gramática general o racional... que prescindiendo de los sonidos, contempla en general las palabras en calidad de signos, y con relación a la idea que presenta cada uno" (TTP, I, $245 a, 248$ a; Bases, I, 270 a).

En cambio no podemos sino aplaudir el deseo de que se dé trato humano a los alumnos. El estímulo de éstos ha de ser la ambición de verse estimados, y su castigo, la vergiienza; y siempre se han de tomar en cuenta las circunstancias y los talentos del estudiante. Otra vez concuerdan las ideas de Jovellanos con las de Locke y forman un contraste

35. TTP, I, 233 b; Bases, J. 268 b-269 b; Bareño, 37, n. 1; Rousseau, Emile, I, 241 y ss.

36. Oracion... sobre la necesidad de unir el estudio de la literatura al de las ciencias, I, 333; Locke, Thoughts, n.o 175.

37. CHC, I, 103 a; Galino, 217. Cf. Condillac, Cours d'études pour l'instruction du Prince de Parme (en Euvres philosophiques de Condillac, ed. Georges Le Roy, I, París, 1947), 398. 
con el mundo que nos describen las novelas picarescas, la Vida de Torres Villarroel y el Fray Gerundio. ${ }^{38}$ Don Gaspar reconoce además la importancia de la recreación para los alumnos (Calatrava, 101, 132; Orde. nanza para el R. I. A., II, 408 b-409 a).

Jovellanos quiere que se fomente la educación fuera de las escuelas por medio de academias, sociedades económicas, museos, bibliotecas, periódicos e imprentas. También el teatro, si se reforma debidamente, puede servir esta misma causa. ${ }^{39}$ Dentro de los lindes que imponen la religión y la moralidad, la libertad del pensamiento y de la prensa debe extenderse y protegerse para que progresen los conocimientos y la educación (Bases, I, 274 b-276 a). Finalmente, la educación se ha de extender a todos según requieran sus profesiones; y debe incluso tratar «de igualar los dos sexos, disipando tantas ridículas y dañosas diferencias como hoy los dividen y desigualan. ${ }^{40}$

Al llegar a este punto ya habrán quedado en claro algunas de las influencias, españolas y extranjeras, en el pensamiento pedagógico de Jovellanos. Hay que partir, por supuesto, de Feijoo, quien entre tantas noticias útiles y charlas divertidas no deja de propugnar la llamada filosofía experimental y clamar contra la rutina y la tradición ciega en materia de enseñanza. Además, muchas de las ideas del P. Luiz Antonio Verney, el famoso Bardadiño o Metodista tan duramente increpado por el P. Isla, coinciden con las de nuestro autor (v. Sarrailh, 190-194). En el Seminario de Vergara vio y admiró éste un modelo de lo que podía ser un establecimiento moderno de enseñanza, por lo menos para nobles (Carta a D. Antonio Valdés [1791], IV, 178 b); y entre sus mentores y amigos era constante la preocupación por la educación. Don Pablo de Olavide se había ocupado de la reforma universitaria en Sevilla, y en las colonias establecidas por él en Sierra Morena se introdujo la enseñanza primaria obligatoria. ${ }^{41}$ El Conde de Campomanes señaló a la edu-

38. Calatrava, 64, 213-231; D, 7. III. 95, II, 17; Locke, Thoughts, nos. 45-48, 52, 56 (cf. 78); Diaz-PlaJa, $80-81$.

39. Bases, I, 275 a-276 a: D, 31.XII.96, II, 305-306. Cf. Calatrava, 114. Rousseau, Emite, I, 417, en cambio Ilama a las academias ades écoles subliques de mensonges».

40. MSC 3, n. 58, carta 1; Memoria pala el arregio de la pulicía de los espectáculos y diversiones públicas, y sobre su origen en España, I, 484 a.

41. Pablo de Olavide, "Informe de Olavidz sobre la ley agraria», ed. y pról. de Ranón Carande Boletín de la Real Academia de la Historia, CXXXIX (1956), 356; Gervasio de Artínano y de Galdácano, Jovellanos y su España, Madrid, 1913, 88; Ba.erio, 19; Joaquín Costa, Colectivismo agrario en España, Madrid, 1898, 118-119. 
cación un papel fundamental en la reconstrucción económica del país, pidiendo que se instruyera a los artesanos y se les proporcionaran manuales técnicos. ${ }^{42}$ Bastante más radicales son las ideas del Conde de Cabarrús. Exige la enseñanza primaria universal, la libertad amplia de pensamiento y palabra, la educación de ciudadanos, la formación física junto con la intelectual y un método pedagógico basado en el placer y la dulzura. Son duras sus reclamaciones contra las escuelas de religiosos: "Aquella edad necesita del amor y de las entrañas del padre; ¿y la confiamos a los que juraron no serlo?» Asimismo ataca a las universidades y pide la abolición de estas «cloacas de la humanidad, y que solo han exâlado sobre ella la corrupción y el error." ${ }^{43}$

Las obras de Locke tuvieron, desde luego, una influencia fundamental en el pensamiento de Jovellanos, y no sólo el Essay Concerning Human Understanding, sino también los Thoughts Concerning Education, de los que existió una traducción francesa propiedad de don Gaspar y anotada por él. ${ }^{44}$ Aunque en general tenía de Rousseau una opinión poco halagüeña leyó con evidente aprobación el Emile (D, 7.X.94, I, 495). Todas estas obras debe de haberlas conocido Jovellanos mucho antes de producir sus escritos padagógicos, a juzgar por lo que sobre ellas le escribe su amigo Meléndez Valdés en 1776 y 1779 (B. A. E., LXIII, 73, 85). Por los años de 1790 leía las obras pedagógicas de Condillac y Condorcet y la Enquiry Concerning Political Justice de William Godwin. ${ }^{45}$ Habiendo dicho esto, sin embargo, hay que destacar la originalididad de Jovellanos respecto a las dos fuentes extranjeras más conocidas, Locke y Rousseau. Estos autores condenan la enseñanza organizada en instituciones y prefieren la doméstica, que, según el escritor francés, es la natural. ${ }^{46}$ En cambio, Jovellanos cree que los internados promueven más la enseñanza por la calidad superior de sus maestros, por el ambiente intelectual y por la uniformidad del método pedagógico. La desventaja que tienen es de carácter práctico más bien que moral: limitan necesariamente la instrucción de las masas. Por esto prefiere Jovellanos instituciones

42. [Pedro Rodriguez Campomanes], Discurso sobre la educación popular de los artesanos, y su fomento, Madrid, 1775, especialmente 66 y ss., 147-160.

43. Francisco Cabarrús, Cartas sobre los obstáculos que la naturaleza, la opinión y las leyes oponen a la felicidad pública, Vitoria, 1808, 67-98; las citas de 81 y 83 ;

44. Miguel Adellac y Gonzalez de Agüero, "Estudio preliminar" a Manuscritos inéditos de Jovellanos. Plan de educacion de la nobleza trabajado de Orden del fiey en 1798, Gijón, 1915, $60 \mathrm{n} .1$.

45. V. por ej. D, I, 386, 451; D, II, 236, 274, 371, 427. De Jovellanos y Godwin trato en Jovellanos and . 1964. (Transactions of the American Philosophical Society, New Series, vol. 54, part. 7).

46. Locke, Thotghts, n.0 70; Rousseau, Emile, 1, 19 y II, 293. Sobre los peligros de la educación doméstica compárense Thoughts, n.0 89, Emile. I, 37, y Elogio fúnebre del señor Marqués de los Llanos de alguazas, I, $283 \mathrm{~b}-284 \mathrm{a}$. 
públicas, abiertas y gratuitas. ${ }^{47}$ Todas sus teorías pedagógicas se refieren a las escuelas, y son por esto mismo de aplicación más amplia que las de Locke y de Rousseau, quienes, requiriendo los servicios constantes del padre o del ayo, sólo se dirigen en efecto a aquel pequeño sector social capaz de sufragar los gastos de tal enseñanza. Es evidente que no se puede llegar así a la educación de un pueblo entero, como se lo proponía Jovellanos.

Además, y aunque fue Jovellanos quien introdujo en la literatura pedagógica española el término y en gran parte el concepto de educación cívica (Galino, 237-238), es cierto que los conocimientos no son para él, como para Locke, "lo de menos» en la educacion (Locke, Thoughts, n. 147). Los demás desiderata de Locke -la virtud, la sabiduría, la buena crianza- también son importantes para Jovellanos; pero proponiénclose éste resolver problemas prácticos y con frecuencia económicos, la adquisición de conocimientos tiene necesariamente un papel importantísimo en su pensamiento pedagógico. No se contenta Jovellanos, como Rousseau, con facilitarle al alumno esta adquisición (Emile, I, 336, 424); debe haberla hecho para ser miembro útil de la sociedad. Este proceso ha de empezar con la adolescencia y no aplazarse cuanto sea posible, como en el caso del joven Emilio: los programas pedagógicos de Jovellanos, por rigurosos que nos parezcan, se han formado para adolescentes.

La tendencia práctica se manifiesta no sólo en los escritos de Jovellanos sino también en sus realizaciones concretas en el campo de la enseñanza. Ya en 1781 había propuesto el fomento de ésta y sobre todo de las matemáticas, la economía política y las ciencias fisicas como "medios de promover la felicidad" de Asturias; y al año siguiente sugirió que la sociedad económica del Principado pensionase a dos jóvenes para estudiar en Vergara y en el extranjero y luego enseñar matemáticas y ciencias naturales en un seminario noble asturiano (Medios, II, 451-452; Discurso... sobre... el estudio de las ciencias naturales, I, 303 b-304 a). Al ser desterrado de la corte en 1790 empezó a trabajar con más ahinco por la creación de una escuela técnica en Gijón, y con la ayuda de su hermano Francisco de Paula y del ministro de Marina D. Antonio Valdés, logró inaugurar el Real Instituto Asturiano de Náutica y Mineralogía el 7 de

47. Elogio finebre del... Marqués de los Llanos, I, 283 b-284 a; Medios, II, 452 a; TTP, I, 234 b. 
enero de 1794. ${ }^{48}$ Esta escuela no sólo pretendía formar técnicos sino también había de servir de modelo para futuros establecimientos del mismo tipo. ${ }^{49}$ Las ceremonias de apertura conmovieron profundamente a Jovellanos:

«El discurso empezó a las nueve; estaba yo bastante sereno, y a juzgar por el efecto fue bien leído, porque sacó algunas lágrimas de ternura. Yo mismo me sentí muchas veces forzado a reprimirlas, y alguna vez me obligó a interrumpirle, pero con grande aumento del interés general» (D, 7.I.94, I, 370).

La originalidad del Instituto consistía en la importancia que daba a las matemáticas y ciencias naturales básicas para la navegación y la mineralogía; pero también se estudiaban humanidades, dibujo, inglés y francés (Noticia del R. I. A., II, 389 b; Ordenanza para el R. I. A., II, 412 a). Las humanidades se aprendían en castellano y con ejemplos españoles. También en el Cours d'études pour l'instruction du Prince de Parme de Condillac las humanidades francesas habían de preceder a las latinas; la innovación de Jovellanos está en la omisión del latín y el énfasis en las humanidades castellanas (Galino, 259), que hace de él el primero que piensa seriamente "en incluir la lengua y la literatura española en los planes de estudio» (Caso, "Humanidades», 108).

El Instituto no era una escuela secundaria de tipo general sino la primera escuela técnica de España con fines pedagógicos que transcendiesen los inmediatamente prácticos de las escuelas militares y de pilotos; y su fundador es «el primero que acierta a crear en España un establecimiento de educación al servicio de una concepción realista de los estudios». Se trata, en efecto, de un esfuerzo por secularizar la educación española, reducir los estudios teológicos y jurídicos y aumentar los científicos de aplicación industrial (Galino, 239-242). Los contemporáneos de Jovellanos entendieron perfectamente este carácter de múltiple innovación; la aversión de algunos se manifestó aun antes de la apertura del Instituto y no dejó después de hostigar a su fundador. ${ }^{50}$ Los diarios y las cartas de Jovellanos atestiguan las frecuentes intrigas de sus enemigos, sobre todo de los que tenían relación con el Santo Oficio, los cuales no tardaron en hallar ocasión de registrar la biblioteca del Instituto.

48. V, Exposición al ministro de Indias sobre estableciniento de un consulado en Gijón, II, 515 b516 a; Informe sobre el beneficto del carbón de piedra y ttilidad de su comercio, II, 467; Borrador y copia de la representación..., V, 226 b-228 b; D, passim; Fermin Canella y Secades, Historia de la Uni. versidad de Oviedo y noticias de los establecimientos de Enseñanza de su distrito, 2,a ed., Oviedo, 1903 345-349; Ceán, 183-189; Galino, 240.

49. Discurso sobre el estudio de la geografía histórica, I, 325 b.

50. Noticia del Real Instituto Asturiano, II, 387 a; Oración... sobre la necesidad de unir el estudir de la literatura al de las ciencias, I, 330 a; D, passim. 
La hostilidad de tales grupos puede que contribuyera a la prisión de Jovellanos en 1801, aunque hay que notar que entre los que apoyaron la escuela también figuraban clérigos.

En los años que entre 1790 y 1801 pasó Jovellanos en Gijón, el Instituto era su ocupación constante. Después de su apertura lo visitaba cada día y tomaba parte en la enseñanza de humanidades y lenguas extranjeras (Ceán, 52). Arreglaba detalles de administración y disciplina, buscaba maestros y fondos, pedía libros e instrumentos científicos. Al volver de los largos años de ausencia forzada dedicó los postreros meses de su vida a la reconstrucción de la escuela, arruinada por la guerra y por la incuria oficial; y en uno de sus últimos escritos pide el apoyo del público para el Instituto y le promete la cuarta parte de su sueldo. ${ }^{51}$

Como continuación de la obra del Instituto proyectó Jovellanos una Academia Asturiana, que parece haberse reunido por lo menos una vez, en 1801, y que había de estudiar varios aspectos de la vida del Principado. Entre los manuscritos jovellanistas de la Biblioteca Pública de Gijón se conserva un borrador autógrafo de carta, en la que señala como tareas iniciales la formación de un diccionario del bable y otro geográfico. ${ }^{52}$

En 1797 tuvo parte don Gaspar en la creación de una escuela primaria gratuita para muchachos en Gijón con fondos que para este fin había dejado su amigo D. Fernando Morán-La Bandera, Abad de Santa Doradía; y el mismo año logró que su hermana Sor Josefa fundase otra escuela parecida para niñas. ${ }^{53}$ Antes, como miembro de las sociedades económicas sevillana y matritense, se había interesado por la creación de escuelas en que las niñas pobres pudiesen aprender a ganarse honradamente la vida.

Los principales escritos pedagógicos de Jovellanos son ellos mismos medidas tomadas en situaciones específicas. Fruto de su viaje oficial a Salamanca como miembro del Consejo de Ordenes en 1790 es el Reglainento para el Colegio de Calatrava, ahora nuevamente editado por Don José Caso González; el Tratado teórico-práctico de enseñanza se escribió en 1802 para un concurso de la Sociedad Económica mallorquina; las Bases para la formación de un plan general de instrucción pública se

51. Exhortación al público para reparar los daños causados en el $R$. Inst.o Asturiano (5 de noviembre de 1811), V, 261 b.

52. D, 27.V.94, I, 434; 10.X.96, II, 283; 20-XI.00, II, 500; 8.I.01, II, 503; O, II, 346 b; MSA 3.

53. Ceán, 77, 227-229; Julio Somoza García-Sala, Documentos para escribir ta biografia de Jovellanos, 2 vols., Madrid, 1911, I, 173 y ss.; Canella, 445-447. Cf. D, 11.III.95, I, 544-54:. 
presentaron en 1809 a la comisión de instrucción pública de la Junta Central. Abundantes cartas, discursos y otros escritos tratan igualmente de problemas específicos en ocasiones determinadas.

Algunos de los esfuerzos educativos de Jovellanos tuvieron resultados bastante efímeros. El Colegio de Calatrava no vivió mucho tiempo; el Tratado teórico-práctico se quedó sin terminar y no pudo presentarse a a la Sociedad Económica; las Bases para un plan de instrucción pública se presentaron a la Junta Central poco antes que ésta cayera del poder (Perz, 38; TTP, I, 267 b , n." 1; Bases, I, $276 b$, n. ${ }^{\circ}$ 1). El Real Instituto Asturiano funcionó según su plan original hasta 1803, cuando, desterrado y encarcelado su fundador, se redujo su dotación y se limitó la enseñanza a la de una sencilla escuela de náutica. Sus vicisitudes después de su restablecimiento en 1810 son demasiadas para contadas aquí. ${ }^{54}$ Junto con el Seminario de Vergara sirvió de modelo para varias pequeñas escuelas secundarias de enseñanza práctica, mantenidas por el Estado y por la Iglesia; tuvo cierta resonancia en el extranjero, especialmente en Hispanoamérica; y fue, en opinión de varios autores, el precursor de las escuelas técnicas superiores. ${ }^{55}$ También ofreció un ejemplo de enseñanza secundaria laica mantenida por el Estado, en lo cual, si no en su plan de estudios, fue precursor de los establecimientos que luego habían de llamarse «institutos». Las ideas de Jovellanos tuvieron resonancia, aunque de eficacia dudosa y bastante discutida, en las reformas pedagógicas proyectadas y en parte realizadas por Godoy y después por el Marqués de Caballero. Las Bases influyeron en los proyectos pedagógicos del gobierno de José Bonaparte y en los de las Cortes de Cádiz, cuya comisión de enseñanza presidió el amigo y admirador de Jovellanos, Manuel José Quintana. Después, en 1824, volvieron a consultarse sus obras para formar un nuevo plan de estudios universitarios. ${ }^{56}$ Así, directa e indirecta-

54. Memoria en defensa de la Junta Central, I, 561 a, 608 b; Exposición para a restauración de lo estudios en el Instituto y terminación del mevo edificio, V, 260 b; Somoza, Documentos, I, 13, 275-279; Rafael Lama y Leña, Reseña histórica del Instituto Jovellanos de Gijón, Gijón, 1902, 49, 54; Canella, 3:4-367.

55. Perz, 38-39; Bareño, 71; Artínano, 172-173; Enrique de Gandía, «Las ideas políticas de Jovellanosn, La nueva democracia (Nueva York), XXXIX, N.o 3 (julio 1959), 37; Julio V. González, «Influencia de as ideas de Jovellanos en la gesta emancipadora argentinam, en Jovellanos: su vida y su obra, 688; Yaben, 128.

56. Bareño, 19 y ss.; José Caso González, «Rectificaciones y apostillas a mi artículo «Jovelianos y la Inquisicións, Archivum, IX (1959), 93; Eduardo Ovejero y Maury, prólogo a Obras escogidas de Jovellanos, Madrid, 1930, XX; Miguel Sánchez, Examen teológico-crítico de la obra del Excmo. Señor D. Cándido Nocedal titulada Vida de Jovellanos, Madrid, 1881, 158; Bases, I, 268 a, n. 1, 276 b, n. 1 (notas 
mente, contribuyó la obra de Jovellanos a las reformas educativas en el siglo XIX.

La verdad es que Jovellanos, sin resolver los problemas de la enseñanza española, contribuyó a una nueva manera de enfocarlos. Absorbió lo mejor que podían ofrecerle españoles y extranjeros y lo adaptó a las condiciones de su patria. Propuso ideas nuevas, a veces atrevidas, que formaban parte de un programa general, aunque nada doctrinario, de reforma política y económica. Prescindió de lo visionario y utópico para atenerse a lo práctico y útil. Y en el Real Instituto Asturiano, que hoy lleva su nombre, ofreció un ejemplo vivo de la enseñanza moderna. Su obra pedagógica encierra, por consiguiente, parte esencial de su pensamiento total y debe figurar en toda historia intelectual de la España de su tiempo.

de C. Nocedal); Galino, 219; Perz, 43.45; Enrique G. Rendueles, Jovellanos y las ciencias morales $y$ políticas: estudio critico, Madrid, 1913, 52-53. Nocedal, y con él Galino, niegán la influencia de Jovellanos en los proyectos de Cádiz, si bien ésta es menos categórica que Nocedal, cuyos comentarios, además, tal vez se refieran sólo a la Regencia. Pero los detalles que da Perz, a quien no se le puede qcusar de favorable al centralismo ni al hiberalismo, parecen poner fuera de duda esa influencia. 